\title{
Computerisation of the College records
}

\section{The College Library}

Records of the College and its antecedent associations include a wealth of material on the formulation of psychiatric policy dating from 1841 . Enquiries concerning this information make up a high proportion of the College Library's usage.

These data are in the form of minutes of meetings of the institution. As they had never been indexed and were consequently extremely difficult to access, it was agreed that a database be developed by the Library staff to store and facilitate the dissemination of the information. The project was tackled in two stages, the first being the 'current' material, i.e. from 1971 when the RMPA obtained its Collegiate status. The second stage was to be the creation of an archival database emphasising the historical content of the material.

\section{Stage 1: The Policy Index 1971-}

Our brief was to develop an in-house online database using the existing ICL System 25 mini computer and Apex software - the only system available in the College. The data were to be compiled from the minutes of the College Council and Executive and Finance Committee meetings, these meetings being the source of all major College policies, guidelines, statements, etc.

It soon became apparent that the flexibility of the database would be limited by the constraints of the software system-the main problem being that searchable fields were limited to 50 characters. To overcome this, the original plan to treat each meeting as a separate record was abandoned and a subject approach was followed. Thus, each new topic discussed at a meeting was treated as an individual record. Each record was divided initially into three searchable fields of up to 50 characters in length and one text field of unlimited size. A typical record being:

Ref. No. 01213

Subject Benzodiazepines and Dependence

Keywords RCPsych statement, Substance abuse, Bulletin

Text EFCC 167/87,41 (May)-E\&F recd info on consensus mtg on "Benzodiazepines and Dependence..."

The reference number is in essence an accession number for quick access to a particular record where the number is known. The subject field is searchable in strings of up to eight characters. The keywords supplement the subject field and act as a key to the text field. To ensure consistency, a thesaurus of keyword terms was compiled. The text field is essentially a precis of the actual meeting minute. Additionally the date and number of the minute are provided.

Since the project began in 1985 , some 300 meeting minutes, together with innumerable reports, have been read, abstracted and added to the database, resulting in over 1,300 topic records relating to subjects discussed in committee.

The increasing use of the system by the Library in response to members' enquiries, as well as usage by other College departments, drew attention to a significant omission: actual references to College policy documents appearing in the College Bulletin were not easy to access. This problem has been remedied by adding another screen to the system offering the extra application. For example:

$\begin{array}{ll}\text { Title } & \begin{array}{l}\text { Benzodiazepines and De- } \\ \text { pendence }\end{array} \\ \text { Bulletin Ref } & \text { 1988 May pp 205 }\end{array}$

Compilation of this bibliographic data has now been completed, resulting in a very useful spin-offan indexed print-out of all the major College policy documents since 1971 (Royal College of Psychiatrists Library, 1989).

\section{Stage 2: The Archival Database 1841- 1971}

Drawing on our experience with the Policy Index, a different approach was taken in designing a database for the early 'College' records. It was anticipated that these records would be of prime interest to serious medical and historical researchers rather than used for administrative purposes by other departments of the College. There was thus no necessity for the two databases to be linked. It was agreed that initially the MPA and RMPA Annual and Council meetings would be abstracted. A new approach was taken emphasising the archival aspect of the minutes and the needs of users to approach them from both the chronological and the subject viewpoints.

The acquisition by the Library of an IBM PS/2 computer workstation provided the opportunity to consider using a more versatile software system which would accommodate the amount of data to be abstracted while offering better retrieval. As no suitable off-the-shelf package could be found, it was agreed that the company IME would supply a version of their TINlib system, especially customised to 
our design. TINlib offers unrestricted record size as well as repeatable fields of up to 1,000 characters. The sophisticated retrieval facilities, including free text searching, are particularly applicable to our needs.

The minutes under consideration cover Annual meetings 1841-1970 and Council meetings 18871971. This database treats each meeting as a separate record within which eight fields are available. In practice not all of these fields are used in every record. However the first four fields are always used for they cover the year and title of the meeting, the exact date, the place and the source of this information, for example

Meeting title and number: 1893 52nd annual

Place: Buxton, Derbyshire meeting

Date of the meeting: 1893 July 28

Source: Journal of Mental Science Vol XXXIX pp 588-60

The other four fields allow for details of attending members, reports of officers and committees, appointment of new committees and other business to be recorded.

The minutes themselves cover a variety of topics. Attending members include those who gave papers or who took an active part in an Annual meeting in some other way; the reports field records that a report was presented by a particular officer or committee, with a precis of the information where this is other than routine. The small committee field includes committee names and dates. Other business consists of matters arising in general discussion at the meetings.

\section{Conclusion}

In spite of limitations, both systems are proving useful. Records covering almost 150 years are now accessible. Topics can be pinpointed and where the computerised abstract does not offer sufficient detail, the enquirer can be directed to the original minute or discussion document.

Although the amount of data abstracted to build up these databases in order to create a comprehensive record of College development is very great, the task is almost complete. Members of the College are welcome to consult this information by contacting the Library.

\section{Acknowledgement}

The success of the Policy Index is largely due to the efforts of Mrs Mary Greene, Senior Library Assistant, whose knowledge of the College has proved invaluable in compiling the database. Thanks are also due to Vanessa Cameron, the Secretary, for her support and helpful suggestions.

\section{Reference}

Royal College of Psychiatrists Library (1989) Statements, Guidelines and Policy Documents of the College.

Susan Floate

Librarian

Margaret Harcourt Williams

Archivist

\section{Election of President}

\section{Notice to Fellows and Members}

Fellows and Members are reminded of their rights under the Bye-laws and Regulations, as follows:

\section{Bye-law XI}

The President shall be elected annually from amongst the Fellows.

\section{Regulation XI}

(1) As soon as may be practicable after the first day of January in any year the Council shall hold a nomination meeting and shall ... nominate not less than one candidate and not more than three candidates...

(2) Between the first day of January in any year and the date which is four clear weeks after the nomination meeting of the Council, written nominations, accompanied in each case by the nominees' written consent to stand for election, may be lodged with the Registrar, provided that each such nomination is supported in writing by not less than twelve Members of the College who are not members of the Council.

(3) An election by ballot shall be held in accordance with the provisions of the Regulations.

The nominating meeting of the Council will be held on 19 January 1990 and the last date for receiving nominations under (2) above will therefore be 16 February 1990. Dr J. L. T. Birley is in his third year of office as President and is therefore ineligible for re-election.

\section{Election to the Fellowship}

Candidates for election to the Fellowship are considered annually by the Court of Electors.

Candidates may not make a personal approach to the College for election, but must be nominated by two sponsors, who must be Fellows of the College.

Sponsors should apply in writing to the Registrar for the relevant forms. Completed nominations should be submitted to the Registrar by 30 September 